\title{
Coexistence of multiple ureteral and ureterocele stones in a patient
}

\author{
Zafer Turkyilmaz ${ }^{1,2}$, Suleyman Yesil ${ }^{1,2}$, Ramazan Karabulut ${ }^{1,2^{*}}$, Fazli Polat ${ }^{1,2}$, Kivanc Seref $^{1,2}$, , Hayrunnisa Oral ${ }^{1,2}$ \\ and Kaan Sonmez ${ }^{1,2}$
}

\begin{abstract}
Background: Uroterocele causes atony and stagnation in the ureter, thus predisposing the patient to stone formation. Multiple calculi in uroteroceles are common in adults but very rare in children.

Case presentation: We describe the case of a 3-year-old boy who presented with hematuria and was found to have multiple ureteral and ureterocele stones. The diagnosis was made during endoscopic lithotripsy. A holmium/yttriumaluminum-garnet (Ho-YAG) laser was used to excise the uroterocele and for lithotripsy.
\end{abstract}

Conclusions: In appropriate cases, minimally invasive techniques, for example, Ho-YAG laser lithotripsy and ureterocele excision may be preferred.

Keywords: Ureterocele, Ureter, Stone, Laser lithotripsy

\section{Background}

A ureterocele is a dilation of the submucosal ureter due to a delay in Chawall's membrane absorption. This anomaly causes atony and stagnation in the ureter, thus predisposing the patient to stone formation [1]. Ureteroceles and stone association is common in adults but rarely seen in children [2]. In this case report, we describe the discovery of multiple ureteral and uroterocele stones in a 3-year-old boy.

\section{Case presentation}

A 3-year-old boy was admitted with hematuria of 1-month duration. The patient had no previous history of urinary tract infection, hematuria, or abdominal pain. The physical examination was unremarkable, and all laboratory tests were normal, except for hematuria. A plain abdominal radiograph was normal. Urinary tract computed tomography $(\mathrm{CT})$ revealed normal renal parenchyma and a normal pelvis. At the lower end of the left

\footnotetext{
*Correspondence: karabulutr@yahoo.com

1 Department of Pediatric Surgery, Faculty of Medicine, Gazi University, Besevler, 06550 Ankara, Turkey

Full list of author information is available at the end of the article
}

ureter, it showed a $4 \mathrm{~mm} \times 24 \mathrm{~mm}$ opacity, as well as an $11 \times 6 \mathrm{~mm}$ opacity extending into the bladder adjacent to the first opacity (Fig. 1). Transurethral lithotripsy was performed. During the cystoscopy procedure, no left ureteral orifice was observed. However, a balloon-like ureterocele containing numerous millimeter-sized stones was observed (Fig. 2). The ureterocele was excised by holmium/yttrium-aluminum-garnet (Ho-YAG) laser lithotripsy. The laser energy and frequency were $0.6-1.0 \mathrm{~J}$ and $5-10 \mathrm{~Hz}$, respectively. During the excision of the ureterocele, a large number of millimeter-sized stones were observed in the ureter. On the CT, they had the appearance of a single stone. After the excision of the ureterocele with the Ho-YAG laser, the orifice of the left ureter was made more prominent. The stones were spontaneously laid down in the bladder, and a 3F double-J stent was placed in the collecting system. To reduce the operative time, stone extraction was not performed. Instead, the fragments, which were smaller than 1-2 mm, were left to pass spontaneously. The total operative time was $30 \mathrm{~min}$. The double-J stent was removed 1 month later. There was no recurrence of the stones and no additional pathology at follow up. 


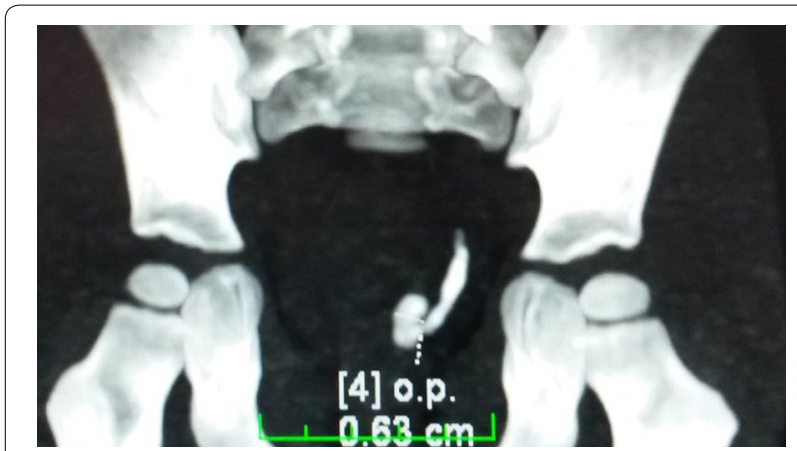

Fig. 1 One stone image in left ureter in CT

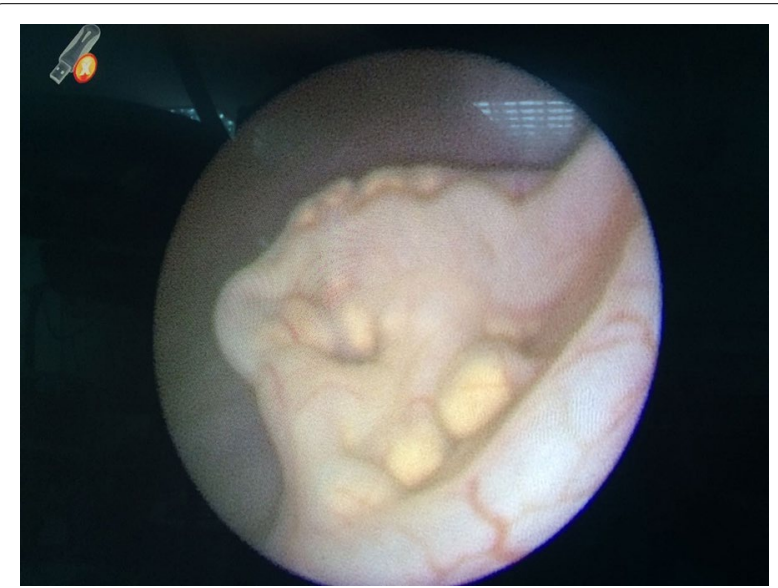

Fig. 2 Left ureterocele containing multiple stones during cystoscopy procedure predisposing the patient to stone formation [1]. Ureteroceles and stone association is common in adults but rarely seen in children [2]. In this case report, we describe the discovery of multiple ureteral and uroterocele stones in a 3-year-old boy. The presence of a single stone in a single ureterocele has been reported in adults, with an incidence of 4-39\% [3]. However, similar occurrences are rare in children. A stone in a ureterocele usually grows asymptomatically and causes hematuria and obstruction [4]. Sometimes, the stone can result in spontaneous erosion of the ureterocele [1]. Ultrasound, an intravenous pyelogram, and CT can be used to confirm the diagnosis of an uretorecele containing multiple stones. However, a lack of experience on the part of the radiologist may allow an ureterocele with multiple stones to go undetected $[3,4]$. Our patient was just 3 years old, making this is the third youngest case report of multiple ureteral and ureterocele stones in the literature. It is also the first time laser lithotripsy has been used for ureterocele excision. In the present study, the small size of the multiple stones in the ureterocele meant there was no need for laser lithotripsy to break the stones. Both lithotripsy and ureterocele excision can be done with a Ho-YAG laser. However, in the limited number of pediatric patients in the literature, open surgery is generally preferred (Table 1).

\section{Conclusion}

A ureterocele and ureteral stones should be considered in patients who present with hematuria. In appropriate cases, minimally invasive techniques, for example, HoYAG laser lithotripsy and ureterocele excision may be preferred.

\section{Discussion}

A ureterocele is a dilation of the submucosal ureter due to a delay in Chawall's membrane absorption. This anomaly causes atony and stagnation in the ureter, thus

Table 1 Clinical presentation and treatment modality of the reported cases in literature

\begin{tabular}{|c|c|c|c|}
\hline & Age & Clinical presentation & Treatment modality \\
\hline Our case & 3 years & Hematuria & $\begin{array}{l}\text { Transurethral excision of the ureterocele with laser and } \\
\text { stone extraction }\end{array}$ \\
\hline Moskowitz et al. [5] & 3 years & $\begin{array}{l}\text { Recurrent urinary infection, urinary retention, abdominal } \\
\text { tenderness }\end{array}$ & Open surgery, ureterocele excision, and stone removal \\
\hline Sarsu et al. [4] & 6 years & Hematuria with bladder stone? & Open surgery, ureterocele excision, and stones removal \\
\hline Scuderi et al. [6] & 7 years & $\begin{array}{l}\text { Flank pain, hematuria, and infection. Cobra head appear- } \\
\text { ance intravenous urography }\end{array}$ & $\begin{array}{l}\text { Cystoureteroscopy and percutaneous cystolithotomy for } \\
\text { duplex system uterocele for } 8.5-\mathrm{cm} \text { stone }\end{array}$ \\
\hline Gilbert et al. [7] & 8 months & Prenatal diagnosis and bilateral hydronephrosis & $\begin{array}{l}\text { Transurethral incision of the two ureteroceles and extrac- } \\
\text { tion of the left ureterocele stone }\end{array}$ \\
\hline Stafford et al. [8] & 7 years & $\begin{array}{l}\text { Episodic lower abdominal pain, urgency, frequency, and } \\
\text { dysuria }\end{array}$ & $\begin{array}{l}\text { Right side duplex system ureterocel with 11-mm stone. } \\
\text { Not confirmed }\end{array}$ \\
\hline
\end{tabular}




\section{Authors' contributions}

ZT, SY, RK, and FP gave idea and collected the patient's data and analyzed them. SK and HO followed the patients postoperatively. RK wrote the paper. $\mathrm{KS}$ is guarantor with revision. They all approved the final version of the manuscript.

\section{Funding}

This study had no funding from any resource.

\section{Availability of data and materials}

The datasets used and/or analyzed during the current study are available from the corresponding author on reasonable request.

\section{Compliance with ethical standards}

\section{Competing interests}

The authors declare that they have no competing interests.

\section{Ethics approval and consent to participate}

Aproval by the institutional ethical committee has been waived (being a retrospective case report). Our institution does not require ethical approval for this case report. Written informed consent for the patient's participation was given by his parents.

\section{Consent for publication}

Written informed consent for the publication of this data was given by the patient's parent.

\section{Author details}

1 Department of Pediatric Surgery, Faculty of Medicine, Gazi University, Besevler, 06550 Ankara, Turkey. ${ }^{2}$ Department of Urology, Faculty of Medicine, Gazi University, Ankara, Turkey.
Received: 30 October 2019 Accepted: 24 February 2020

Published online: 28 June 2020

\section{References}

1. Mandal S, Goel A, Kumar M, Goyal NK, Sankhwar SN (2012) Spontaneous erosion of ureterocele wall by stone: rare images. Urology 80(4):e43-e44

2. Shamsa A, Asadpour AA, Abolbashari M, Hariri MK (2010) Bilateral simple orthotopic ureteroceles with bilateral stones in an adult: a case report and review of literature. Urol J 7:209-211

3. Gharbi Y, Gargah T, Boukesra T, Hellal Y, Sayed S (2013) Ureterocele containing a stone in a duplex system. Saudi J Kidney Dis Transpl 24:984-987

4. Sarsu SB, Koku N, Karakus SC (2015) Multiple stones in a single-system ureterocele in a child. APSP J Case Rep 6(2):19

5. Moskowitz B, Bolkier M, Levin DR (1987) Ureterocele containing calcified stone. J Paediatr Surg 11:1047-1048

6. Scuderi MG, Yankovic F, Featherstone N, Smeulders N (2013) Voluminous, "cobra-head" stone in a duplex system ureterocele: combined cysto-ureteroscopic and percutaneous cystolithotomy approach. J Laparoendosc Adv Surg Tech A 23(5):484-485

7. Gilbert WB, Hernanz-Schulman M, Pope JC 4th (2001) Development of small calculi in an infant with bilateral single system ureterocele. J Urol 166:880-881

8. Stafford AM, Logan H, O'Grady MJ (2014) "Cobra head" stone. J Pediatr 164(2):428.e1

\section{Publisher's Note}

Springer Nature remains neutral with regard to jurisdictional claims in published maps and institutional affiliations.

\section{Submit your manuscript to a SpringerOpen ${ }^{\circ}$ journal and benefit from:}

- Convenient online submission

- Rigorous peer review

- Open access: articles freely available online

- High visibility within the field

- Retaining the copyright to your article

Submit your next manuscript at $\gg$ springeropen.com 